\title{
Hypersecretory villous adenoma as the primary cause of intestinal intussusception and McKittrick-Wheelock syndrome
}

\author{
Susana Sanchez Garcia MD, Pedro Villarejo Campos MD, Maria del Carmen Manzanares Campillo MD, \\ Aurora Gil Rendo MD, Virginia Muñoz Atienza MD, Esther Pilar García Santos MD, \\ Francisco Javier Ruescas García MD, Jose Luis Bertelli Puche MD
}

\begin{abstract}
Ttestinal invagination or intussusception is the most common cause of intestinal obstruction in children and represent $5 \%$ of adult cases. This intestinal obstruction is due to a lesion in the intestinal mucosa that initiates intussusception or intestinal invagination $(90 \%$ of adult cases are malignant). Moreover, villous adenomas, which represent malignant potential, are found within these lesions of intestinal mucosa. There are variants of villous adenomas known as hypersecretory adenomas, which are described as intestinal lesions located more frequently in the rectum and distal colon. In addition, these variant adenomas can cause hypersecretory diarrhea and an electrolyte disturbance known as McKittrick-Wheelock syndrome.
\end{abstract}

\section{CASE PRESENTATION}

A 77-year-old woman was hospitalized due to rectal prolapse and a large rectal polypoid mass, with symptoms of rectal bleeding that developed weeks before. Forty-eight hours after hospitalization, she experienced progressive clinical worsening. On physical examination, a painful abdomen without any sign of peritonitis was noted. After rectal touch, a rough, hard tumour located $5 \mathrm{~cm}$ from the anus was palpated with some bleeding.

Laboratory data revealed slight leukocytosis with neutrophilia (leukocytes $12.7 \times 10^{9} / \mathrm{L}, 88 \%$ neutrophils); anemia (hemoglobin $91 \mathrm{~g} / \mathrm{L}$, hematocrit $27.3 \%$ ); a worsening of previous renal insufficiency (blood urea nitrogen $55.3 \mathrm{mmol} / \mathrm{L}$, creatinine $415.5 \mu \mathrm{mol} / \mathrm{L}$ ); marked hypokalemia (2.9 mmol/L) with normonatremia (146 mEq/L); metabolic acidosis with normal lactic acid and high anion GAP levels ( $\mathrm{pH} 7.16$, bicarbonate $17.8 \mathrm{mmol} / \mathrm{L}$, lactic acid $7 \mathrm{~g} / \mathrm{L}$, anion GAP $21.4 \mathrm{mg} / \mathrm{dL})$.

Abdominal computed tomography (CT) with intravenous contrast was performed and revealed a giant hiatal hernia, intestinal loops and significant stomach distention, and colon distention to the rectal level. CT imaging also suggested significant colorectal invagination (Figure 1).

At the rectal level, imaging revealed a mass approximately $4 \mathrm{~cm}$ in diameter that appeared to correspond to the polypoid lesion visualized in a previous colonoscopy focused at the head of the invagination.

Given the clinical, laboratory and radiological data, and after progressive worsening, the woman underwent emergent surgery. Suspecting tumoural complications (eg, perforation, intestinal obstruction, intestinal pain, etc), a laparotomy revealed a rectal tumour that was hard on palpitation, suggestive of rectal intussuception.

Thus, given the exceedingly low possibility of manual reduction and the presence of ischemic lesions in the rectal wall, an anterior ultralow resection and terminal colostomy (Hartman's intervention) was performed (Figure 2).

Pathology results documented a villous and adenomatous polyp $3.7 \mathrm{~cm}$ in size, with sites of moderate dysplasia associated with areas of ischemic colitis and lymphatic glands with a nonspecific reactive pattern. The patient was diagnosed with McKittrick-Wheelock syndrome related to a hypersecretory villous adenoma that caused rectal intussuception and secondary intestinal obstruction.

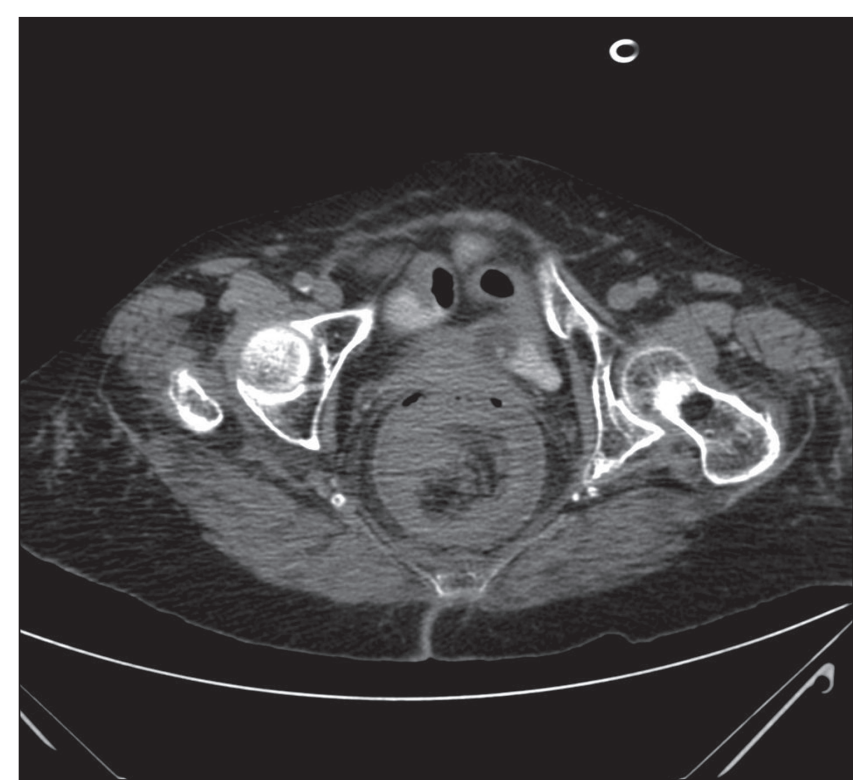

Figure 1) Computed tomography image suggesting the presence of a colorectal invagination

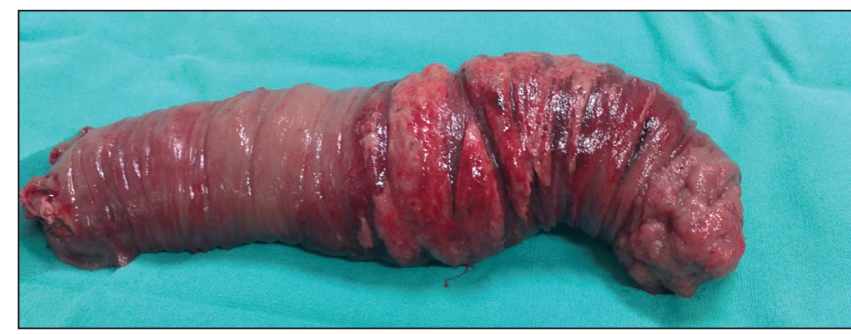

Figure 2) Portion of resected bowel demonstrating the intussusception

\section{DISCUSSION}

Intestinal invagination is defined as prolapse of a part of intestine into an adjacent portion. In adults, only $5 \%$ of intestinal obstruction symptoms are due to intussuception, and $90 \%$ of intestinal intussuception cases are due to pathological processes. In $66 \%$ of cases, intussuception of the bowel is caused by a malignant lesion. However, in the small intestine, causative lesions of the invagination progress from benign neoplasic lesions (Meckel diverticulum or inflammatory lesions) to intestinal adhesions. In fact, malignant lesions represent 30\% of invaginations in the small intestine (1-6).

Our patient presented with atypical symptoms, experiencing intestinal obstruction secondary to rectal intussuception, together with significant alterations in electrolyte levels (acute kidney failure, marked

Hospital General Universitario, Ciudad Real, Spain

Correspondence: Dr Susana Sanchez Garcia, Hospital General Universitario, Valencia Street, No6 4A, 13002 Ciudad Real, Spain.

Telephone 66-117-9720, e-mail susisg_83@hotmail.com

Received for publication May 21, 2013. Accepted June 16, 2013 
hypokalemia and metabolic acidosis, with normal lactic acid and high anion GAP levels) $(1,2,5)$.

These electrolyte alterations fulfilled the diagnostic criteria for McKittrick-Wheelock syndrome, first described in 1954, and referenced hypersecretory diarrhea symptoms as well as a state of severe electrolyte depletion in relation to large rectal villous adenomas. These lesions have a high potential for malignancy and may appear asymptomatically. Among these lesions, villous adenomas represent $3 \%$ to $6 \%$ of all colonic tumours, of which only $3 \%$ are hypersecretory adenomas $(7,8)$. Villous adenomas causing McKittrick-Wheelock syndrome are characterized by their hypersecretory capacity. Hypersecretion of fluids and electrolytes is due to an increase in cyclic AMP produced by adenylate cyclase and elevated levels of prostaglandin E2, a mediator involved in the development of secretory diarrhea $(9,10)$. This electrolyte depletion causes a typical syndrome characterized by dehydration, confusion and even death $(7,10)$. In the present case, the lesion was caused by a hypersecretory villous adenoma, which not only led to symptoms of intestinal obstruction, but was also associated with electrolyte alterations typical of McKittrick-Wheelock syndrome.

The diagnosis of intussusception was based on imaging tests such as CT: a part of the intestine prolapsed into another (double-wall image) is considered pathognomonic of intussusceptions, distinguishing the head of the invagination among the edematous intestines in $70 \%$ of cases (10-16). The management of intestinal intussusception depends on the patient's clinical status and the time of symptom onset. Conservative treatment is indicated in cases for which there are no clinical signs or lesions on the head of demonstrable intussusception(s). These data are considered to be predictors of spontaneous symptom resolution; there have been reports of intussusceptions with these features that have resolved spontaneously and were treated conservatively with periodic radiological monitoring. However, surgical

\section{REFERENCES}

1. Wang N, Cui XY, Liu Y, et al. Adult intussusception: A retrospective review of 41 cases. World J Gastroenterol 2009;15:3303-8.

2. Yakan S, Caliskan C, Makay O, et al. Intussusception in adults: Clinical characteristics, diagnosis and operative strategies. World J Gastroenterol 2009; 15:1985-9.

3. Dvorkin LS, Knowles CH, Scott SM, et al. Rectal intussusception: Characterization of symptomatology. Dis Colon Rectum 2005;48:824-31.

4. Seguridad en los pacientes quirúrgicos Tratado de cirugía. Fundamentos biológicos de la práctica quirúrgica moderna. Sabiston, Cap. 71:2063-4.

5. Guillén Paredes MP, Campillo Soto A, Martín Lorenzo JG, et al. Adult intussusception - 14 case reports and their outcomes. Rev Esp Enferm Dig 2010;102:32-40.

6. Morera-Ocón FJ, Hernández-Montes E, Bernal-Sprekelsen JC. Intestinal invagination in adults: Presentation of a case and a review of the Spanish literature. Cir Esp 2009;86:358-62.

7. Murature Stordiau GE, Suárez Alecha J, Zazpe Ripa C, et al. Acute renal failure and profund hypokalemia caused by a villous adenoma in the rectum: McKittrick-Wheelock syndrome. Rev Esp Enferm Dig 2009;101:78-9.

8. Dagan A, Reissman P. Giant secretory villous adenoma of the rectum and sigmoid presenting as McKittrick-Wheelock syndrome. Int J Colorectal Dis 2010;25:909-10.

9. Chand M, Bradford L, Nash GF. Intussusception in colorectal cancer. Clin Colorectal Cancer 2008;7:204-5. treatment is indicated for the majority of intestinal intussusceptions due to the risk of an intestinal ischemia and the possibility of a malignant lesion in the head of the intussusception, which can go unnoticed.

Treatment of hypersecretory villous adenomas is mainly surgical. Use of indomethacin in patients with McKittrick-Wheelock syndrome has been reported to inhibit or decrease electrolyte secretion in individuals who refuse surgery. Among the surgical options, transanal resection (transanal endoscopic microsurgery) using a posterior presacral approach (anterior tumours) or mucosectomy, and abdominal surgery for large tumours, are preferred. This type of benign tumour has the potential to become malignant; the only treament option that has been proven to be effective is surgery involving complete excision of the lesion, which results in normalization of electrolyte levels and prevents progression to a malignant tumour $(17,18)$.

\section{CONCLUSIONS}

Intestinal intussusception in adults is rare; therefore, considering a malignant intestinal lesion is important because it is the most common cause. Its diagnosis is based on visualization of an area of intestine prolapsed into another (wall or double-wall thickening) using CT imaging.

Within intestinal mucosal lesions, $<1 \%$ of hypersecretory villous adenomas represent malignant potential. In fact, they can cause symptoms of hypersecretory diarrhea with electrolyte disturbances characteristic of McKittrick-Wheelock syndrome, in addition to the possibility of intestinal intussusception given their significant size.

Surgery is the definitive treatment for intestinal intussusceptions and villous adenomas. It improves electrolyte disturbances and eliminates the possibility of malignancy.
10. Kim SW, Shin HC, Kim IY, et al. CT findings of colonic complications associated with colon cancer. Korean J Radiol 2010;11:211-21.

11. Seguridad en los pacientes quirúrgicos Tratado de cirugía. Fundamentos biológicos de la práctica quirúrgica moderna. Sabiston, Cap. 45; p.1180-1198

12. Tresoldi S, Kim YH, Blake MA, et al. Adult intestinal intussusception: Can abdominal MDCT distinguish an intussusception caused by a lead point? Abdom Imaging 2008;33:582-8

13. Takeuchi K, Tsuzuki Y, Ando T, et al. The diagnosis and treatment of adult intussusception. J Clin Gastroenterol 2003;36:18-21.

14. Thomas AW, Mitre R, Brodmerkel GJ Jr. Sigmoidorectal intussusception from a sigmoid lipoma. J Clin Gastroenterol 1995;21:257.

15. Wang LT, Wu CC, Yu JC, et al. Clinical entity and treatment strategies for adult intussusceptions: 20 years' experience. Dis Colon Rectum 2007;50:1941-9.

16. Jiménez-Rodríguez RM, Díaz-Pavón JM, González JM, et al. Adenoma velloso gigante secretor de iones. Revisión de la literatura y estado actual de su tratamiento. Rev Esp Enferm Dig 2007;99:616-17.

17. Rea JD, Lockhart ME, Yarbrough DE, et al. Approach to management of intussusception in adults: A new paradigm in the computed tomography era. Am Surg 2007;73:1098-105.

18. Martínez García R, Gómez Abril SA, Trullenque Juan R, Martínez Mas E, Martínez Abad M. McKittrick-Wheelock syndrome: Giant secretor rectal adenoma. Cir Esp 2010;87:117-9. 


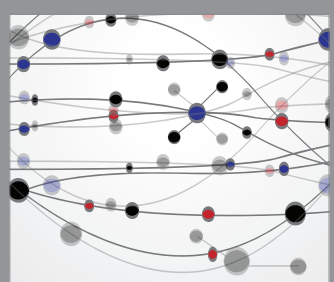

The Scientific World Journal
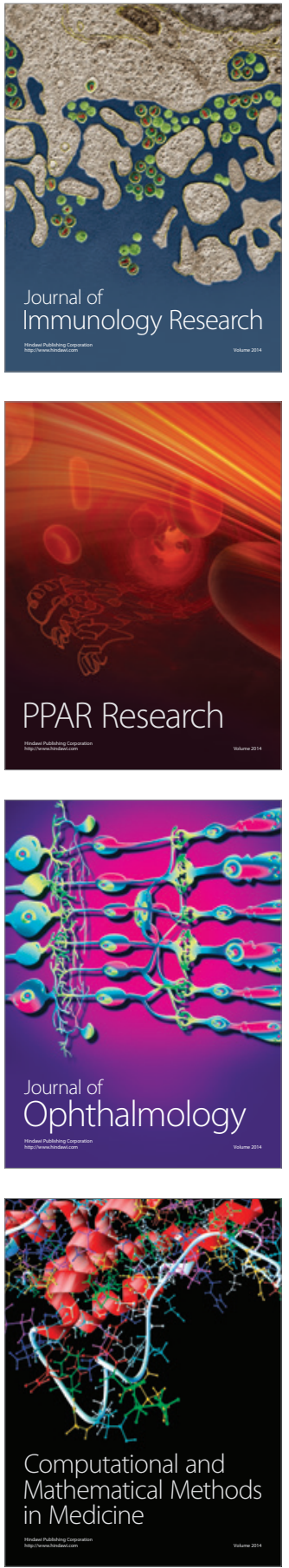

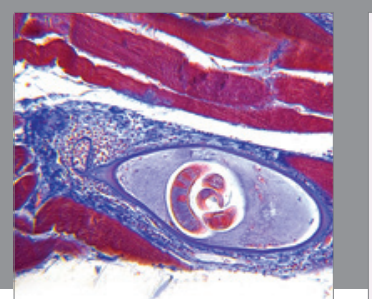

Gastroenterology Research and Practice

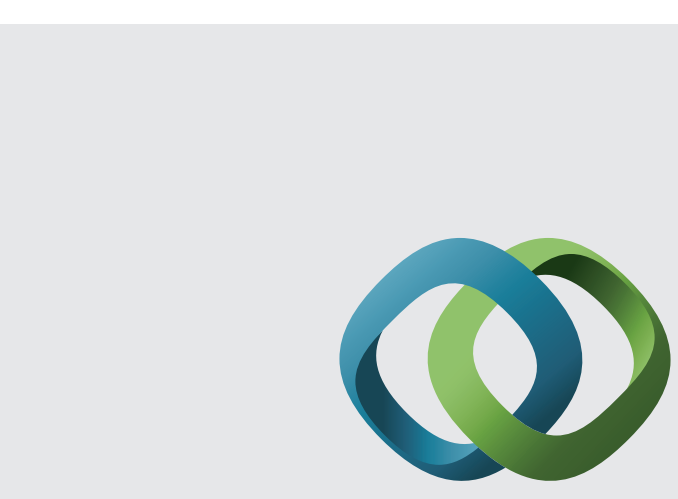

\section{Hindawi}

Submit your manuscripts at

http://www.hindawi.com
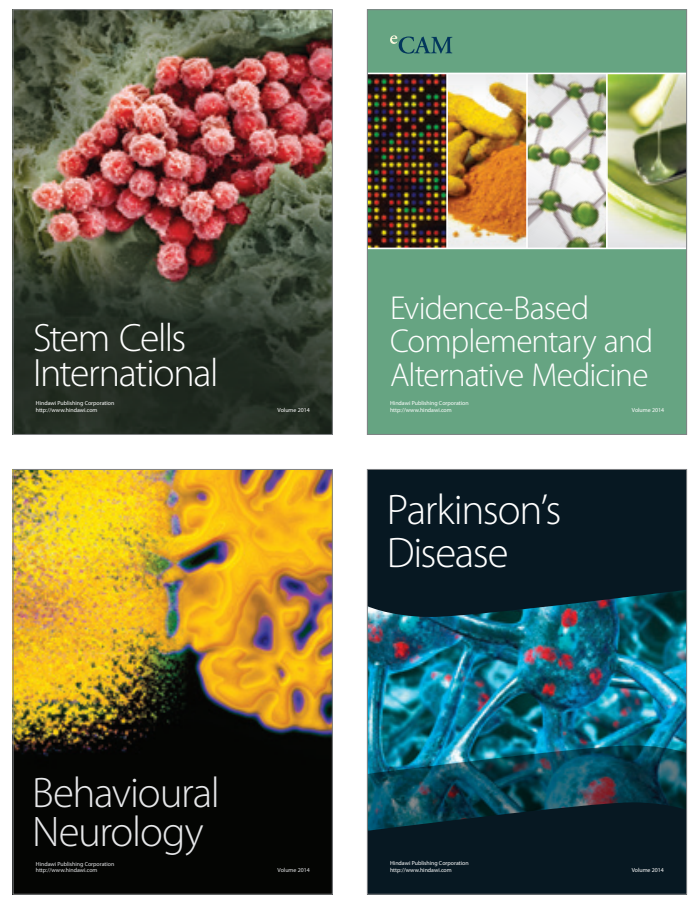
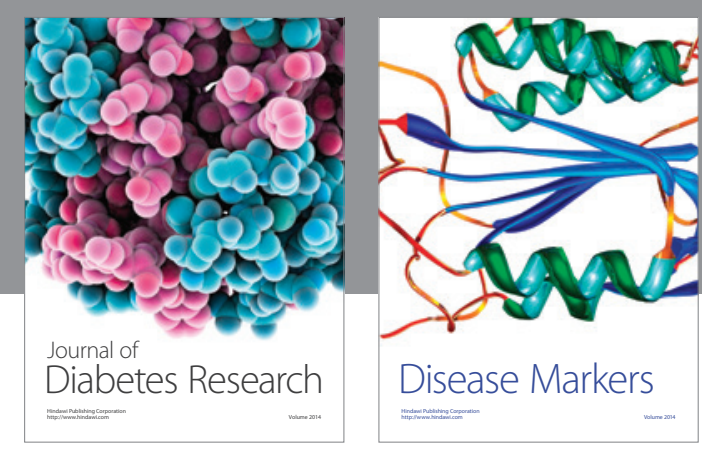

Disease Markers
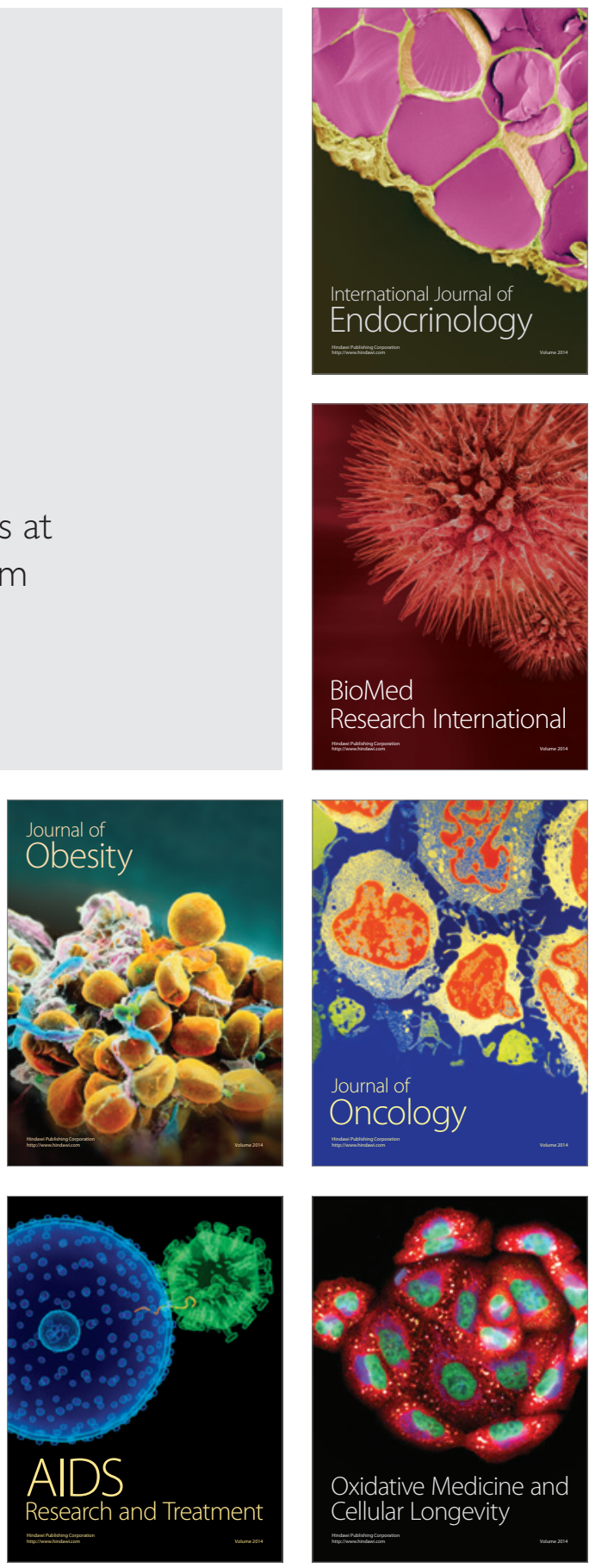